\title{
Comparison of Immune Responses to the PCV2 Replicase-Capsid and Capsid Virus-Like Particle Vaccines in Mice
}

\author{
Bo-Kyoung Jung ${ }^{1}$, Hye-Ran Kim ${ }^{1,2}$, Young-Hyeon Lee ${ }^{1}$, Hyun Jang ${ }^{3}$, and Kyung-Soo Chang ${ }^{1 *}$ \\ ${ }^{1}$ Department of Clinical Laboratory Science, Catholic University of Pusan, Busan 48513, Republic of Korea \\ ${ }^{2}$ Department of Clinical Laboratory Science, College of Medical Sciences, Daegu Haany University, Daegu 38610, Republic of Korea \\ ${ }^{3}$ WooGene BEG, Seoul 07299, Republic of Korea
}

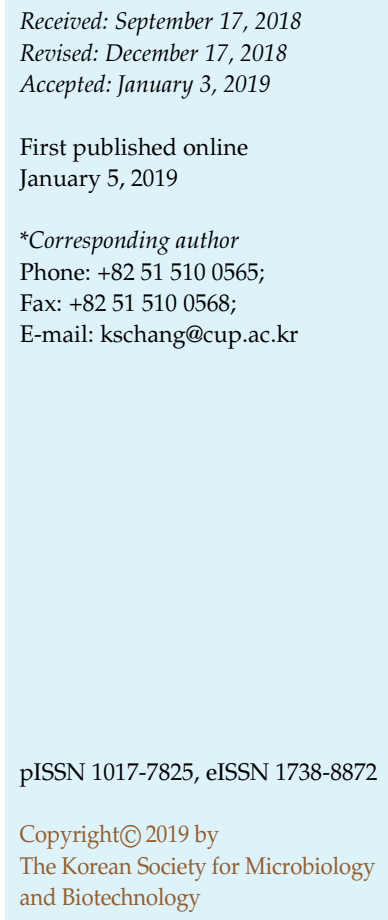

Porcine circovirus type 2 (PCV2) is the causative agent of postweaning multisystemic wasting syndrome (PMWS) in pigs. Replicase (Rep) proteins are considered essential for viral replication. Capsid (Cap) protein is the primary immunogenic protein that induces protective immunity. Little is known about comparison on the immunogenicity of PCV2 Rep and Cap fusion protein and Cap protein. In the present study, recombinant baculoviruses expressing the Rep-Cap fusion protein (Bac-Rep-Cap) and the Cap protein (Bac-Cap) of PCV2 were constructed and confirmed with western blot and indirect fluorescence assay. Immunogenicities of the two recombinant proteins were tested in mice. The titers of antibodies were determined with a PCV2-specific enzyme-linked immunosorbent assay (ELISA) and a serum neutralization assay. The IFN- $\gamma$ response of immunized mice was measured by ELISA. The mice immunized with the Bac-Rep-Cap and Bac-Cap successfully produced Cap-specific immunoreaction. The mice immunized with the Bac-Cap developed higher PCV2-specific neutralizing antibody titers than mice injected with the Bac-Rep-Cap. IFN- $\gamma$ in the Bac-Rep-Cap group was increased compared to those in the Bac-Cap group. Vaccination of mice with the Bac-Rep-Cap showed significantly decreased protective efficacy compared to the Bac-Cap. Our findings will indubitably not only lead to a better understanding of the immunogenicity of PCV2, but also improved vaccines.

Keywords: Baculovirus, capsid, post-weaning multisystemic wasting syndrome, porcine circovirus type 2, replicase, vaccine

\section{Introduction}

Porcine circovirus type 1 and type 2 (PCV1 and PCV2) belong to the genus Circovirus of the family Circoviridae and are non-enveloped, single-stranded, circular DNA viruses with an icosahedral capsid [28]. PCV1 is considered to be nonpathogenic while PCV2 is the causative agent of postweaning multisystemic wasting syndrome (PMWS), proliferating and necrotizing pneumonia (PNP), porcine dermatitis and nephropathy syndrome (PDNS), and porcine respiratory disease complex (PRDC) [1].

Protein expression of PCV2 has been described for three ORFs. The ORF1 gene encodes two replicase (Rep and Rep') proteins of $35.7 \mathrm{kDa}$ and $17 \mathrm{kDa}[4,18]$ while the ORF2 gene encodes a capsid (Cap) protein of $27.8 \mathrm{kDa}$, which is the only structural protein of the virus [20]. ORF3 protein is a non-structural protein, but is involved in PCV2induced apoptosis through the intracellular activation of the caspase pathways [15].

Generally, Cap protein has been significantly studied as a vaccine antigen against PCV2 infection $[3,8,9,13,25,32]$. Based on comparison of the immunogenicity of the PCV2 Cap and Rep proteins, Rep protein was determined to be a weak immunogen [3]. Due to this insufficient immunity, the effects of the Rep-Cap fusion protein on viral immunogenicity could be investigated as an alternative approach.

Previous study determined that DNA vaccines based on the ORF1 gene have suppressive effects on the immunogenicity of the ORF2 gene in mixed DNA vaccination [23]. 
However, the mixed DNA vaccine induced a decreased response compared to the individual immediate constituent $[22,31]$. The immune suppression might be caused by antigenic competition [22]. Comparison of the cellular and humoral characteristics of the recombinant Rep-Cap protein and Cap protein as a VLP in vivo remain unclear.

As virus-like particles (VLPs) are non-infectious, and are able to elicit humoral and cell-mediated immune responses $[6,27]$, this is a good method for the design of foreign epitope carriers. Baculovirus surface display system has been extensively used for the production of subunit vaccines, especially for VLPs [26]. This system has several advantages in that it is cost-saving to produce, harmless to humans and mammalians [12, 29], and enables proper post-translational modification [16].

The main aim of this study was to construct the PCV2 Rep and Cap fusion protein and the Cap protein alone on the baculoviral envelope. The recombinant baculovirus Bac-Rep-Cap and Bac-Cap were constructed and tested. The potential of Bac-Rep-Cap and Bac-Cap was evaluated by immunization of mice. To our knowledge, this study is described for the first time.

\section{Materials and Methods}

\section{Virus and Cell Lines}

PK15 cells were propagated and maintained in Dulbecco's modified essential medium (DMEM, Welgene, Korea) supplemented with $10 \%$ heat-inactivated fetal bovine serum (FBS, Welgene, Korea) at $37^{\circ} \mathrm{C}$. The strain of PCV2 (GenBank No.: KX828232.1), which was provided by WooGene B\&G, was propagated in PK-15 cells. Spodoptera frugiperda cells (Sf21) (Clontech, USA) were used to propagate the recombinant baculoviruses and were cultured in TNM-FH Insect Medium (Welgene, Korea) supplemented with $10 \% \mathrm{FBS}$ at $27^{\circ} \mathrm{C}$.

\section{Construction of Recombinant Baculovirus Vector}

ORF1 and ORF2 genes were respectively polymerase chain reaction (PCR) amplified from PCV2 strain KU-1605 and applied overlap extension PCR to construct the genes for pBac-Rep-Cap. All primers used in this paper are shown in Table 1. The ORF1ORF2 PCR product was inserted into the corresponding site in the baculovirus transfer vector pBacPAK8 (Clontech, CA). The resulting ORF1-ORF2 fusion open reading frame contains $942 \mathrm{bp}$ of ORF1 followed by $699 \mathrm{bp}$ of ORF2 sequence. To obtain transfer plasmid pBac-Cap, the ORF2 PCR product was digested by BamHI, and constructed using the same method. The recombinant plasmid pBac-Rep-Cap and pBac-Cap were verified by sequencing.

\section{Generation of Baculoviruses}

The recombinant plasmids were used to construct two recombinant baculoviruses, namely, Bac-Rep-Cap and Bac-Cap. Monolayers of Sf21 insect cells were co-transfected with recombinant transfer vectors and AcMNPV DNA using lipofectamine (Clonetech, USA). After $4 \mathrm{~h}$ of incubation, the medium was removed and replaced with $5 \mathrm{ml}$ TNM-FH Insect Medium (Welgene). After 5 days, the supernatant was harvested, and infectious titers were determined with the BD BacPAK Baculovirus Rapid Titer Kit (Clonetech).

\section{Western Blot Analysis}

Sf21 cells were infected with Bac-Rep-Cap or Bac-Cap at a multiplicity of infection (MOI) of 10 . The cells were harvested at $48 \mathrm{~h}$ post infection. After being centrifuged at $8,000 \times g$ for $5 \mathrm{~min}$, cell pellets were mixed with $2 \times$ loading buffer $(125 \mathrm{mM}$ Tris-Cl [pH 6.8], 20\% glycerol, $4 \%$ SDS, $10 \%$-mercaptoethanol, $0.25 \%$ bromophenol blue) and heated at $100^{\circ} \mathrm{C}$ for $5 \mathrm{~min}$. The proteins were separated by sodium dodecyl sulfate-polyacrylamide gel electrophoresis (SDS-PAGE) on 12\% polyacrylamide gel and then transferred onto nitrocellulose membrane (Invitrogen, USA) using semi-dry transfer cell (Bio-Rad, USA) at $1 \mathrm{~V} / \mathrm{cm}^{2}$ for $30 \mathrm{~min}$. The transferred membrane was blocked in blocking buffer (1\% bovine serum albumin) in Tris-buffered saline and Tween 20 [TBS-T]) at $4^{\circ} \mathrm{C}$ overnight and incubated with anti-Cap monoclonal antibodies (1:2000 dilution) in TBS-T for $1 \mathrm{~h}$ at room temperature. HRP-labeled goat anti-mouse antibody (Santa Cruz Biotechnology, USA) was used as the secondary antibody. After washing three times with TBS-T, protein bands were detected using ECL chemiluminescence system (ELIPIS, Korea).

\section{Immunofluorescence Assay}

The Sf21 cells cultured in 8-well chamber slide (Invitrogen) were infected with Bac-Rep-Cap or Bac-Cap recombinant baculoviruses at an MOI of 1 . At $36 \mathrm{~h}$ post infection, the cells were fixed using $4 \%$ paraformaldehyde solution for $30 \mathrm{~min}$ at $37^{\circ} \mathrm{C}$ and then blocked with $3 \%$ bovine serum albumin for $1 \mathrm{~h}$ at room temperature. The cells were incubated with anti-Cap monoclonal antibodies (1:100 dilution) in PBS for $1 \mathrm{~h}$ at $37^{\circ} \mathrm{C}$. After washing three times with

Table 1. Primers used in this study.

\begin{tabular}{llcc}
\hline Primer & Sequence $\left(5^{\prime} \rightarrow 3^{\prime}\right)$ & Restriction site & Benth \\
Rep-Cap F & TTGGATCCATGCCCAGCAAGAAGAG & 1641 \\
Rep-Cap R & TTGGATCCTTAATGATGGTGGTGATGGTGGGGGTTAAGTGG & BamHI \\
Cap F & TTGGATCCATGACGTATCCAAGG & BamHI \\
Cap R & TTGGATCCTTAATGATGGTGGTGATGGTGGGGGTTAAGTGG & BamHI \\
\hline
\end{tabular}


Table 2. Experimental design.

\begin{tabular}{ccclccc}
\hline Groups & $\begin{array}{c}\text { Number of } \\
\text { mice }\end{array}$ & $\begin{array}{c}\text { Recombinant } \\
\text { proteins }\end{array}$ & Adjuvant & Immunization & $\begin{array}{c}\text { Number of } \\
\text { inoculations }\end{array}$ & Concentration \\
\hline 1 & 6 & Bac-Rep-Cap & Complete & IM & 2 & $10^{9}$ PFU \\
2 & 6 & Bac-Cap & Complete & IM & 2 & $10^{9}$ PFU \\
3 & 6 & PBS & Complete & IM & 2 & - \\
\hline
\end{tabular}

IM: intramuscularly; Adjuvant: Freund's complete adjuvant (Sigma-Aldrich, USA); Recombinant protein was administered twice (0, 21 dpi, days after primary immunizaion)

PBS the cells were incubated with goat anti-mouse IgG conjugated with FITC (1/100 diluted in PBS) (Invitrogen) for $1 \mathrm{~h}$ at $37^{\circ} \mathrm{C}$. After rinsing with PBS thoroughly, the cells were observed under a fluorescence microscope (Olympus, Japan).

\section{Mouse Immunization Schedule}

The experimental design is displayed in Table 2. Six-week-old female BALB/c mice were purchased from Samtako, Korea. The mice were SPF grade (specific pathogen-free) and were randomly allocated into three groups of six mice and housed in filter-top cages in isolation rooms under controlled temperature $\left(20-25^{\circ} \mathrm{C}\right)$, humidity $(60-80 \%)$, and fed sterilized food and water. Groups 1 and 2 were intramuscularly vaccinated with $10^{9}$ PFU of Bac-RepCap or $10^{9} \mathrm{PFU}$ of Bac-Cap with Freund's complete adjuvant (Sigma-Aldrich, USA) at a ratio of 50:50 $(\mathrm{w} / \mathrm{w})$ according to the manufacturer's instructions. Group 3, the negative control group, was immunized with $100 \mu \mathrm{l}$ of PBS. At 21 and 42 days after the primary immunization, the serum samples were collected for detection of antibody to PCV2 by ELISA and analyzed for the presence of PCV2-specific neutralizing antibodies. All experiments were done with the approval of the Institutional Animal Care and Use Committee of Catholic University of Pusan (CUP 2018-2).

\section{Indirect ELISA}

Sera was tested through indirect ELISA to assess PCV2-specific antibody. 96-well plates were coated with the purified recombinant Cap protein $(4 \mathrm{ug} / \mathrm{ml})$ in $0.1 \mathrm{M}$ carbonate/bicarbonate buffer $(\mathrm{pH}$ 9.6), and then the plates were blocked with 5\% skim milk in PBS$0.05 \%$ Tween 20 (PBST). The serial 2-fold diluted serum (starting from $1 / 100$ ) was added and incubated at $37^{\circ} \mathrm{C}$ for $1 \mathrm{~h}$. After washing with PBST three times, the plates were treated with HRPconjugated goat anti-mouse IgG $(1 / 5000)$ for $1 \mathrm{~h}$ at $37^{\circ} \mathrm{C}$. Finally, HRP signal was detected using the tetramethylbenzidine (TMB) as the chromogen. The OD value of each well was measured at $450 \mathrm{~nm}$ using a spectrophotometer. Results were analyzed in the ratio of OD450 produced by the serum samples compared to negative control serum $(\mathrm{P} / \mathrm{N})$.

\section{Serum Neutralization Assay}

PCV2-neutralizing activity in mouse anti-sera increased against Bac-Rep-Cap and Bac-Cap and was determined by using an endpoint dilution reduction assay. The serum samples were heat inactivated at $56^{\circ} \mathrm{C}$ for $30 \mathrm{~min}$ and then diluted two-fold and mixed with equal volumes of PCV2-KU1605 (200 TCID 50 ) for $1 \mathrm{~h}$ at $37^{\circ} \mathrm{C}$. The mixture was inoculated to $40-50 \%$ confluent PK- 15 cells cultured in 96-well plates and incubated at $37^{\circ} \mathrm{C}$ for $1 \mathrm{~h}$. Then, the inoculum was removed, cell cultures were washed twice with DMEM and culture medium was added for incubation. After $72 \mathrm{~h}$, the culture plate was fixed with 1:1 acetone/methanol solution at $-20^{\circ} \mathrm{C}$ for $30 \mathrm{~min}$ and blocked with $3 \%$ BSA in PBS for $1 \mathrm{~h}$ at room temperature. The cells were incubated with anti-Cap monoclonal antibodies followed by fluorescein isothiocyanate (FITC)-conjugated anti-mouse IgG (Abcam, UK) as the second antibody. The cells were observed using a fluorescence microscope (Olympus). The neutralization titer was evaluated as the reciprocal of the highest dilution that was able to completely block PCV2-infection in PK15 cells. The neutralization assay was performed as previously described [10].

\section{Cytokine Analysis}

At 21 and 42 days after the primary immunization, samples collected from mice were determined for cytokine analysis. Serum IFN- $\gamma$ levels were detected among the experimental groups using a mouse cytokine ELISA kit (Life Technologies, USA) at 21 and 42 days after the primary immunization according to the manufacturer's instructions..

\section{Statistical Analysis}

All data were presented as averages \pm the standard deviation (SD) of the means, as indicated. Statistical comparisons are made by using Student's $t$-test. P-values of $<0.05$ were considered statistically significant.

\section{Results}

\section{Expression of Recombinant Proteins}

The recombinant Bac-Rep-Cap and Bac-Cap were constructed as described in the methods (Fig. 1) and detected using western blot analysis with anti-Cap monoclonal antibodies. To confirm the expression of the recombinant proteins in insect cells, Sf21 cells were infected separately by Bac-Rep-Cap and Bac-Cap at $10 \mathrm{MOI}$ and harvested $48 \mathrm{~h}$ post infection. As shown in Fig. 2, BacRep-Cap and Bac-Cap, with the predicted molecular weight at approximately $70 \mathrm{kDa}$ and $27 \mathrm{kDa}$, were expressed 


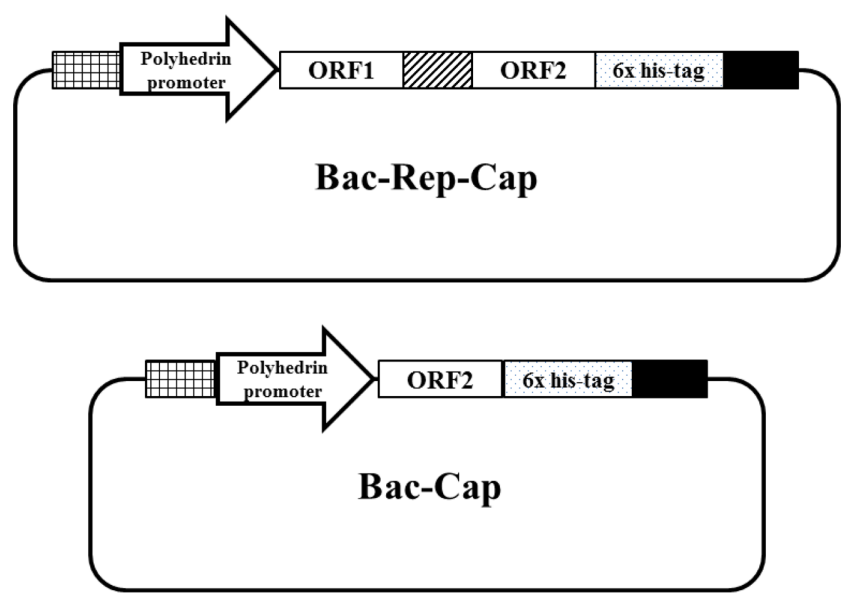

Fig. 1. Schematic representation for the generation of recombinant baculovirus vector Bac-Rep-Cap and Bac-Cap. Rep, replicase protein of PCV2; Cap, capsid protein of PCV2.

efficiently in Sf21 cells. In contrast, specific bands were not detected in uninfected cells.

To determine whether the Cap protein was translocated accurately to the Sf21 cell surface, the cells were cultured on sterile cover slips, infected separately with Bac-Rep-Cap and Bac-Cap at an MOI of 1, and demonstrated to PCV2specific fluorescence $36 \mathrm{~h}$ post infection (Fig. 3). In contrast, green fluorescence was not detected in uninfected cells (negative control). As shown in Fig. 3, Cap protein was directed to the plasma membrane of the infected Sf21 cells. Therefore, the results suggested that all recombinant proteins were successfully expressed.

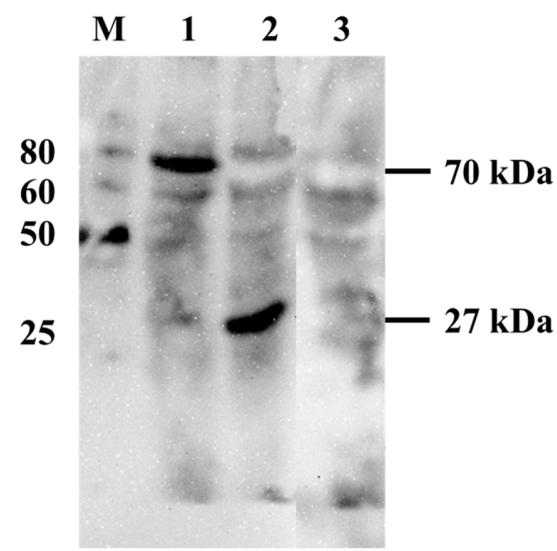

Fig. 2. Western blot analysis of recombinant proteins expressed in Sf21 cells.

The pellet of each cellular lysate of uninfected (lane1), Bac-Rep-Cap (lane2), Bac-Cap (lane3)-infected Sf21 cells were separated on a $12 \%$ SDS-PAGE gel, and transferred to a nitrocellulose membrane for western blot analysis using anti-PCV2 monoclonal antibodies $(1: 2,000)$.

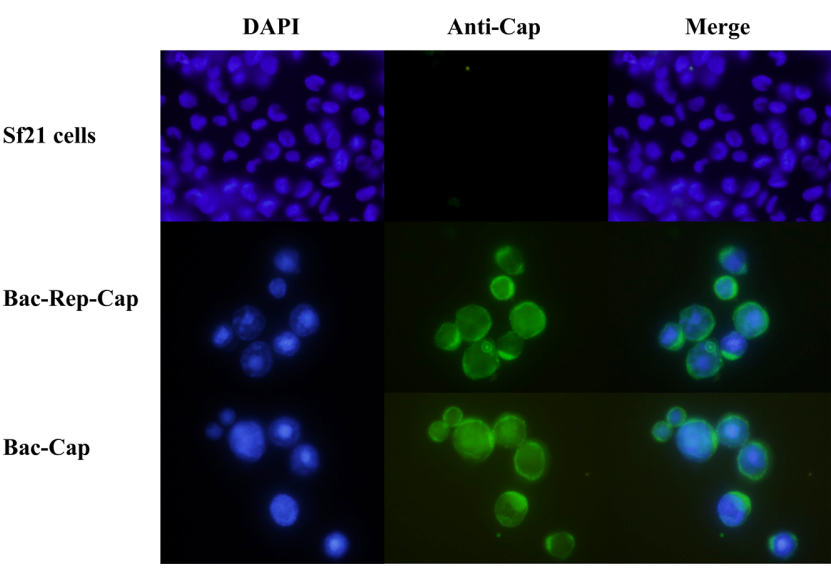

Fig. 3. Immunofluorescence analyses of recombinant proteins expressed in Sf21 cells.

Sf21 cells were infected with Bac-Rep-Cap or Bac-Cap recombinant baculoviruses at an MOI of 1 . At $36 \mathrm{~h}$ after the infection, the cells were fixed using $4 \%$ paraformaldehyde solution and analyzed by IFA using the anti-cap monoclonal antibodies. The cells were then incubated with goat anti-mouse IgG conjugated with FITC as the secondary antibody, and images were acquired using fluorescence microscope.

\section{PCV2-Specific Humoral Immune Responses}

To explore whether Bac-Rep-Cap and Bac-Cap can induce PCV2-specific immune responses in vivo after direct immunization, BALB/c mice were immunized intramuscularly with Bac-Rep-Cap, Bac-Cap, and PBS, respectively. Cap protein-specific ELISA antibodies were monitored at 21 and 42 days after the primary immunization. As shown in Fig. 4, 21 days after the primary immunization, Cap-

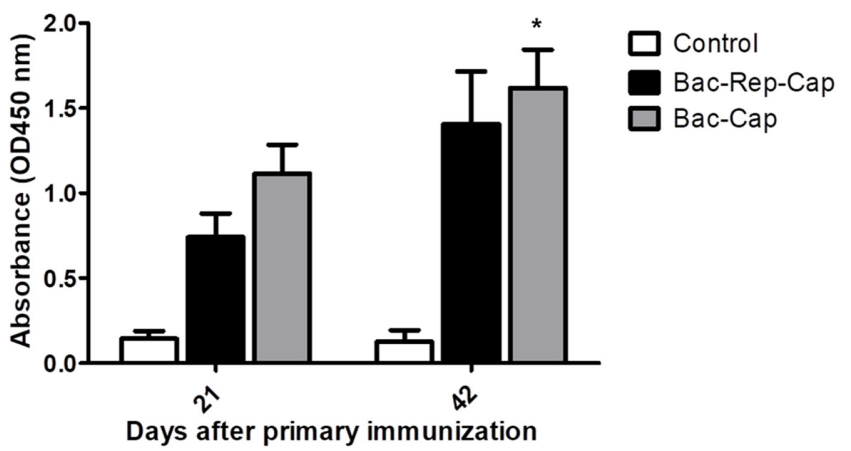

Fig. 4. Cap-specific antibody response in mice detected by indirect ELISA.

BALB/c mice were injected intramuscularly at 0 and 21 days with Bac-Rep-Cap, Bac-Cap, or TNM-FH medium as a negative control. Sera were analyzed for the presence of IgG antibodies by indirect ELISA using the purified recombinant Cap protein. Optical densities were read at $450 \mathrm{~nm}$. All data are means \pm SD. Significant difference is expressed as ${ }^{*} p<0.05$. 


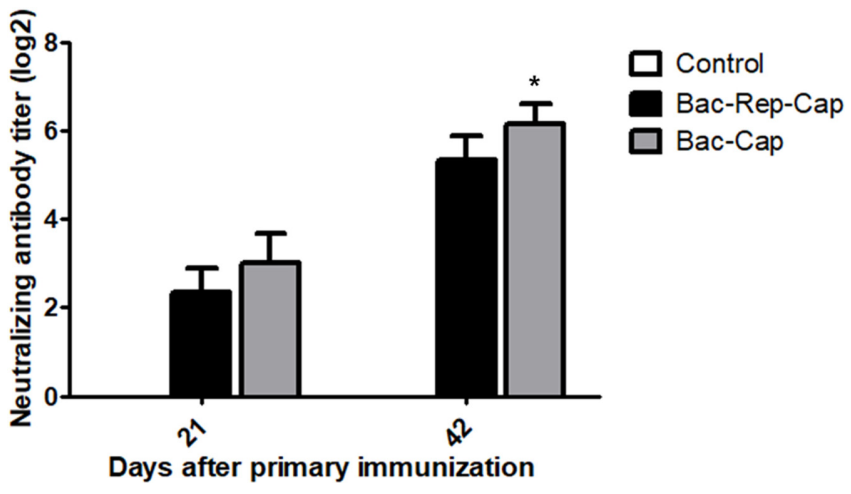

Fig. 5. PCV2-neutralization antibody responses in mice after vaccination with Bac-Rep-Cap and Bac-Cap.

$\mathrm{BALB} / \mathrm{c}$ mice were immunized at 0 and 21 days intramuscularly with Bac-Rep-Cap, Bac-Cap, or TNM-FH medium as a negative control. Sera were used to test PCV2-neutralization antibody titers by using an end-point dilution reduction assay. All data are means $\pm S D$. Significant difference is expressed as ${ }^{*} p<0.05$.

specific antibodies were detected in all the mice immunized with Bac-Rep-Cap or Bac-Cap. Following booster immunization, their mean OD values of 1.407 and 1.618 had remarkably higher ELISA antibody titers than those of the mice inoculated with PBS $(p<0.05)$.

As shown in Fig. 5, the mice immunized with Bac-RepCap or Bac-Cap developed the neutralization antibody titers of serum samples collected at 21 and 42 days after the primary immunization, respectively. Prior to vaccination, neutralizing antibodies were not detected in all mice (data not shown). During the whole experimental period, mice immunized with Bac-Cap developed higher PCV2-specific neutralizing antibody titers than mice injected with BacRep-Cap. No detectable antibody was showed in mice treated with PBS. These results showed that the Cap protein alone was more effective than that with the RepCap fusion protein in inducing PCV2-neutralizing antibody responses in mice.

\section{Cytokine Analysis}

To characterize the cell-mediated immune responses in the mice immunized with Bac-Rep-Cap and Bac-Cap, the levels of some cytokines including IFN- $\gamma$ were determined using a cytokine ELISA kit. As shown in Fig. 6, the mean IFN- $\gamma$ levels of 154.27 and $86.99 \mathrm{pg} / \mathrm{ml}$ were detected in the mice inoculated with Bac-Rep-Cap and Bac-Cap, respectively. IFN- $\gamma$ levels in Bac-Cap were less than those in the BacRep-Cap inoculated group at $42 \mathrm{dpi}$. The levels of IFN- $\gamma$ in the Bac-Rep-Cap and Bac-Cap inoculated groups were higher than those in the negative control mice group at 42

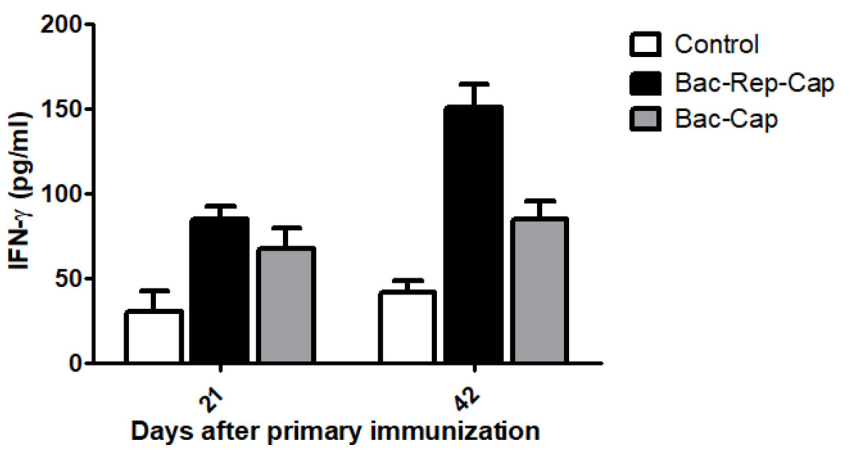

Fig. 6. IFN- $\gamma$ levels in serum of Bac-Rep-Cap and Bac-Cap vaccinated mice.

BALB/c mice were vaccinated at 21 and 42 days with Bac-Rep-Cap, Bac-Cap, or TNM-FH medium as a negative control. Serum samples were used to measure IFN- $\gamma$ by ELISA. All data are means \pm SD.

days after the primary immunization. These results indicated that the Rep-Cap fusion protein is higher than the Cap protein alone in inducing IFN- $\gamma$ expression.

\section{Discussion}

PCV2 is the major infectious agent of postweaning multisystemic wasting syndrome (PMWS), proliferating and necrotizing pneumonia (PNP), porcine dermatitis and nephropathy syndrome (PDNS), and porcine respiratory disease complex (PRDC) [1], also collectively and generally known as porcine circovirus associated disease (PCVAD). There are management strategies for the control of PCVAD, such as the control of co-infections and vaccination. Several types of commercial vaccines have been developed to control PCV2 infection in piglets, including an inactivated PCV2 virus, a killed chimeric PCV1-2 virus [21]. However, there are potential safety problems related with inactivated vaccines, such as incomplete inactivation of viruses and an increased risk for developing an allergic reaction [37]. Therefore, the development of a safe and affordable PCV2 vaccine is an important strategy for the prevention of PMWS.

The baculovirus expression system allows the rapid and efficient generation and the large-scale production of recombinant baculoviruses. Due to the impossibility of baculovirus replicating in mammalian cells, they are an attractive candidate for vaccine development [30]. In particular, the baculovirus expression system has been successfully engineered for the surface display of several proteins $[14,34,35,36]$.

Rep protein is important for replication of PCV [5, 17]. Its 
immunogenic component as an antigen is not only weaker than the Cap protein, but also the vaccination efficacy on the Cap protein is decreased by Rep protein when coadministered to pigs [3]. A previous study also showed that the Rep protein has exhibited suppression of Cap in a mixed DNA vaccine strategy [23]. The immune response of the individual components was reduced by mixing the DNA vaccine [22, 31], because of antigenic competition that takes place during uptake by the host cells, or competition in the antigen processing and presentation pathway [22]. However, all of the above research did not identify whether co-expression of Rep and Cap fusion protein could improve immune responses compared to the Cap protein alone as a subunit vaccine. In this study, the Rep and Cap fusion protein and the Cap protein of PCV2 were successfully cloned and expressed in a baculovirus expression system. Expression of these proteins was detected using western blotting (Fig. 2) and immunofluorescence analysis (Fig. 3).

The results showed Bac-Rep-Cap could induce low levels of the Cap-specific IgG antibody compared with Bac-Cap (Fig. 4). The PCV2-specific neutralizing antibody was assessed at 42 days after the primary immunization. The negative group did not induce neutralization activity throughout the experiment. Bac-Rep-Cap did not exhibit high levels of the neutralization activity compared with Bac-Cap (Fig. 5). This is consistent with the results of a previous study in which Rep protein of Rep-Cap fusion protein suppressed PCV2-specific antibody response [3, 23]. We observed an increased cell-mediated immune response in mice immunized with Bac-Rep-Cap compared with that of mice immunized with Bac-Cap (Fig. 6). ORF1 plasmid immunization enhanced IFN- $\gamma$ at 35 days after the primary immunization [2]. In addition, Meerts et al. [19] reported that high levels of IFN- $\gamma$ have a harmful effect on protective immunity. Upregulation of IFN- $\gamma$ was shown in the peripheral blood mononuclear cells of pigs with PDNS and in the tonsils of PMWS-affected pigs [7, 24].

In summary, this is the first study to compare the recombinant baculovirus displaying Rep and Cap fusion and Cap protein as a PCV2 vaccine. The expressed RepCap fusion proteins on the baculovirus envelope could assemble to form VLPs. The mice immunized with BacRep-Cap and Bac-Cap successfully produced Cap-specific immunoreaction. The humoral immune response of BacRep-Cap was significantly lower than that of Bac-Cap, suggesting that Rep in Rep-Cap fusion protein has a suppressive effect as an antigen. Uncovering such results will indubitably not only lead to a better understanding of the immunogenicity of PCV2, but also improved vaccines.

\section{Acknowledgment}

This work was supported by the National Research Foundation of Korea Grant funded by the Korean Government (NRF-2017R1D1A3B04034362). This research was also supported by the Brain Busan 21 program.

\section{Conflict of Interest}

The authors have no financial conflicts of interest to declare.

\section{Reference}

1. Allan GM, Ellis JA. 2000. Porcine circoviruses: a review. J. Vet. Diagn. Invest. 12: 3-14.

2. An DJ, Song DS, Park BK. 2008. Systemic cytokine profiles of mice vaccinated with naked DNAs encoding six open reading frame antigens of porcine circovirus type 2 (PCV2). Res. Vet. Sci. 85: 503-509.

3. Blanchard P, Mahe D, Cariolet R, Keranflec'h A, Baudouard MA, Cordioli $\mathrm{P}$, et al. 2003. Protection of swine against postweaning multisystemic wasting syndrome (PMWS) by porcine circovirus type 2 (PCV2) proteins. Vaccine 21: 4565-4575.

4. Cheung AK. 2003. The essential and nonessential transcription units for viral protein synthesis and DNA replication of porcine circovirus type 2. Virology 313: 452-459.

5. Cheung AK. 2003. Transcriptional analysis of porcine circovirus type 2. Virology 305: 168-180.

6. Crisci E, Barcena J, Montoya M. 2012. Virus-like particles: the new frontier of vaccines for animal viral infections. Vet. Immunol. Immunopathol. 148: 211-225.

7. Darwich L, Balasch M, Plana-Duran J, Segales J, Domingo M, Mateu E. 2003. Cytokine profiles of peripheral blood mononuclear cells from pigs with postweaning multisystemic wasting syndrome in response to mitogen, superantigen or recall viral antigens. J. Gen. Virol. 84: 3453-3457.

8. Fan H, Xiao S, Tong T, Wang S, Xie L, Jiang Y, et al. 2008. Immunogenicity of porcine circovirus type 2 capsid protein targeting to different subcellular compartments. Mol. Immunol. 45: 653-660.

9. Fenaux M, Opriessnig T, Halbur PG, Meng XJ. 2003. Immunogenicity and pathogenicity of chimeric infectious DNA clones of pathogenic porcine circovirus type 2 (PCV2) and nonpathogenic PCV1 in weanling pigs. J. Virol. 77: 11232-11243.

10. Fort M, Olvera A, Sibila M, Segales J, Mateu E. 2007. Detection of neutralizing antibodies in postweaning multisystemic wasting syndrome (PMWS)-affected and non-PMWS-affected pigs. Vet. Microbiol. 125: 244-255. 
11. Genmei L, Manlin L, Ruiai C, Hongliang H, Dangshuai P. 2011. Construction and immunogenicity of recombinant adenovirus expressing ORF2 of PCV2 and porcine IFN gamma. Vaccine 29: 8677-8682.

12. Groner A, Granados RR, Burand JP. 1984. Interaction of Autographa californica nuclear polyhedrosis virus with two nonpermissive cell lines. Intervirology 21: 203-209.

13. Kamstrup S, Barfoed AM, Frimann TH, Ladekjaer-Mikkelsen AS, Botner A. 2004. Immunisation against PCV2 structural protein by DNA vaccination of mice. Vaccine 22: 1358-1361.

14. Lin YH, Lee LH, Shih WL, Hu YC, Liu HJ. 2008. Baculovirus surface display of sigmaC and sigmaB proteins of avian reovirus and immunogenicity of the displayed proteins in a mouse model. Vaccine 26: 6361-6367.

15. Liu J, Chen I, Kwang J. 2005. Characterization of a previously unidentified viral protein in porcine circovirus type 2-infected cells and its role in virus-induced apoptosis. J. Virol. 79: 8262-8274.

16. Liu LJ, Suzuki T, Tsunemitsu H, Kataoka M, Ngata N, Takeda N, et al. 2008. Efficient production of type 2 porcine circovirus-like particles by a recombinant baculovirus. Arch. Virol. 153: 2291-2295.

17. Mankertz A, Hillenbrand B. 2001. Replication of porcine circovirus type 1 requires two proteins encoded by the viral rep gene. Virology 279: 429-438.

18. Mankertz A, Mankertz J, Wolf K, Buhk HJ. 1998. Identification of a protein essential for replication of porcine circovirus. J. Gen. Virol. 79 (Pt 2): 381-384.

19. Meerts P, Misinzo G, Nauwynck HJ. 2005. Enhancement of porcine circovirus 2 replication in porcine cell lines by IFNgamma before and after treatment and by IFN-alpha after treatment. J. Interferon Cytokine Res. 25: 684-693.

20. Nawagitgul P, Morozov I, Bolin SR, Harms PA, Sorden SD, Paul PS. 2000. Open reading frame 2 of porcine circovirus type 2 encodes a major capsid protein. J. Gen. Virol. 81: 2281-2287.

21. Opriessnig T, Meng XJ, Halbur PG. 2007. Porcine circovirus type 2 associated disease: update on current terminology, clinical manifestations, pathogenesis, diagnosis, and intervention strategies. J. Vet. Diagn. Invest. 19: 591-615.

22. Sedegah M, Charoenvit $Y$, Minh L, Belmonte M, Majam VF, Abot S, et al. 2004. Reduced immunogenicity of DNA vaccine plasmids in mixtures. Gene Ther. 11: 448-456.

23. Shen HG, Zhou JY, Zhang X, Huang ZY, He JL, Yan Y. 2009. Interference of porcine circovirus type 2 ORF2 immunogenicity by ORF1 and ORF3 mixed DNA immunizations in mice. Virology 393: 104-111.

24. Sipos W, Duvigneau JC, Pietschmann P, Schilcher F, Hofbauer G, Hartl RT, et al. 2005. Porcine dermatitis and nephropathy syndrome (PDNS) is associated with a systemic cytokine expression profile indicative of proinflammation and a Th1 bias. Vet. Immunol. Immunopathol. 107: 303-313.
25. Song Y, Jin M, Zhang S, Xu X, Xiao S, Cao S, et al. 2007. Generation and immunogenicity of a recombinant pseudorabies virus expressing cap protein of porcine circovirus type 2 . Vet. Microbiol. 119: 97-104.

26. Strauss R, Huser A, Ni S, Tuve S, Kiviat N, Sow PS, et al. 2007. Baculovirus-based vaccination vectors allow for efficient induction of immune responses against plasmodium falciparum circumsporozoite protein. Mol. Ther. 15: 193-202.

27. Tegerstedt K, Franzen AV, Andreasson K, Joneberg J, Heidari S, Ramqvist T, et al. 2005. Murine polyomavirus virus-like particles (VLPs) as vectors for gene and immune therapy and vaccines against viral infections and cancer. Anticancer Res. 25: 2601-2608.

28. Tischer I, Gelderblom H, Vettermann W, Koch MA. 1982. A very small porcine virus with circular single-stranded DNA. Nature 295: 64-66.

29. Tjia ST, zu Altenschildesche GM, Doerfler W. 1983. Autographa californica nuclear polyhedrosis virus (AcNPV) DNA does not persist in mass cultures of mammalian cells. Virology 125: 107-117.

30. van Oers MM. 2011. Opportunities and challenges for the baculovirus expression system. J. Invertebr. Pathol. 107 Suppl: S3-15.

31. Wang X, Jiang P, Li Y, Jiang W, Dong X. 2007. Protection of pigs against post-weaning multisystemic wasting syndrome by a recombinant adenovirus expressing the capsid protein of porcine circovirus type 2. Vet. Microbiol. 121: 215-224.

32. Wang X, Jiang W, Jiang P, Li Y, Feng Z, Xu J. 2006. Construction and immunogenicity of recombinant adenovirus expressing the capsid protein of porcine circovirus 2 (PCV2) in mice. Vaccine 24: 3374-3380.

33. Wang YP, Liu D, Guo LJ, Tang QH, Wei YW, Wu HL, et al. 2013. Enhanced protective immune response to PCV2 subunit vaccine by co-administration of recombinant porcine IFNgamma in mice. Vaccine 31: 833-838.

34. Xu XG, Chiou MT, Zhang YM, Tong DW, Hu JH, Zhang MT, et al. 2008. Baculovirus surface display of $\mathrm{E}(\mathrm{rns})$ envelope glycoprotein of classical swine fever virus. J. Virol. Methods 153: $149-155$.

35. Xu XG, Tong DW, Wang ZS, Zhang Q, Li ZC, Zhang K, et al. 2011. Baculovirus virions displaying infectious bursal disease virus VP2 protein protect chickens against infectious bursal disease virus infection. Avian Dis. 55: 223-229.

36. Xu XG, Wang ZS, Zhang Q, Li ZC, Zhao HN, Li W, et al. 2011. Baculovirus surface display of $E$ envelope glycoprotein of Japanese encephalitis virus and its immunogenicity of the displayed proteins in mouse and swine models. Vaccine 29: 636-643.

37. Ye Y, Cheng X, Zhang J, Tong T, Lin W, Liao M, et al. 2013. Induction of robust immunity response in mice by dualexpression-system-based recombinant baculovirus expressing the capsid protein of porcine circovirus type 2. Virol. J. 10: 316. 